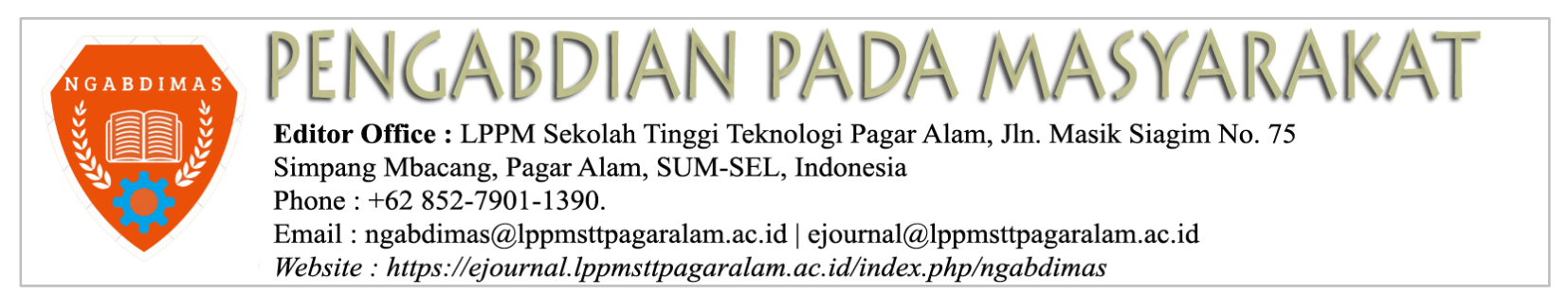

\title{
Pelatihan Maintenance Komputer di SMKN 2 Kota Pagar Alam
}

\author{
Okta Lesva \\ Program Studi Teknik Informatika; Sekolah Tinggi Teknologi Pagaralam (STTP) \\ Jl. M. Siagim No.75 Kel. Karang Dalo, Dempo Tengah, Kota Pagar Alam \\ Telp/Fax: (0730) 621916 \\ e-mail: oktalesva@gmail.com
}

\begin{abstract}
Abstrak
Maintenance komputer merupakan keahlian yang harus dimiliki oleh siswa SMKN 2 Kota Pagaralam, dan praktikum maintenance yang diadakan laboratorium komputer SMKN 2 Kota Pagaralam dianggap belum maksimal karena waktu yang terbatas sehingga civitas akademika STTP dan pimpinan SMKN 2 Kota Pagaralam menggap perlu pelatihan diluar jam pelajaran dan jam praktikum, dan dengan semangat berbagi berdasarkan prinsif Pengabdian pada Tri Dharma maka civitas akademika membantu pelatihan diluar pelajaran dan praktikum sekolah. Metode yang digunakan dengan praktek secara langsung dan siswa yang tidak paham dapat langsung bertanya pada narasumber. Pada pelaksanaannya menggunakan metode pre dan pos tes untuk efektifitas pelatihan, dari pre tes diketahui siswa memahami tentang maintenance tetapi masih banyak bagian materi yang belum benar-benar dipahami sehingga ini menjadi kesempatan bagi civitas STTP untuk melakukan pengabdian. Pada akhir pelatihan dilakukan pos tes hasilnya siswa mampu memahami dan menjelaskan kembali materi dan mampu paham dengan baik perangkat keras dan perangkat lunak komputer.
\end{abstract}

Kata kunci-Maintenance, Civitas, Praktikum, Siswa, STTP, Komputer.

\section{PENDAHULUAN.}

Perkembangan teknologi informasi dan komunikasi (TIK) khususnya teknologi yang mendukung terlaksananya kegiatan (pendukung) pekerjaan saat ini sangat banyak dan menawarkan kemudahan-kemudahan sesuai ke unggulannya masing-masing, salah satunya adalah teknologi sistem komputer ini dapat di manfaatkan untuk berbagai kegiatan, hampir tidak ada yang tidak bisa di kerjakan oleh komputer, terbukti seluruh kegiatan manusia saat ini hampir segalanya, segala kegiatan, segala profesi sudah menggunakan komputer dan mengaplikasikan program tertentu dari mulai komputer atau program yang sangat sederhana sampai dengan sistem komputer dan program dengan konfigurasi yang sangat kompleks, dari komputer yang tidak saling terhubung (personal), tergabung dalam jaringan LAN, MAN, dan WAN, dari software hanya di aplikasikan oleh satu PC sampai dengan sistem yang terdistribusi dan client server, tentunya itu semua untuk mendukung kegiatan manusia, untuk memudahkan.Media ini sangat banyak sekali digunakan di sebagai sarana pembuatan media pendukung informasi distribusi yang sangat familiar.

Pelatihan pengelolaan sistem dan maintenance komputer ini merupakan pemberian pemahaman awal bagi pengelolaan komputer diharapkan walau pun para siswa ini siswa daerah tetapi dapat mandiri, artinya diharapkan pada saat nanti turun di dunia kerja Alumni SMKN 2 Kota Pagar Alam ini tak hanya menjadi pemakai sistem komputer saja tetapi selain pemakai pada saat terjadi kerusahan atau kekurangan yang terjadi pada sistem komputernya mereka tidak tergantung pada pihak lain, dalam hal ini mampu menanganinya terlebih dahulu tanpa bantuan pihak lain, kecuali apa bila terjadi ke rusakan yang memerlukan penanganan yang khusus sebab itulah maka pelatihan ini terlaksana, pada dasarnya seluruh sistem pembelajaran sudah termasuk tentang pengelolaan dan maintenance ini tetapi untuk memberikan kesempatan kepada dosen STTP untuk berbagi dan mungkin terdapat sesuatu yang terlewati atau terlupakan oleh guru di dalam kelas maka SMKN 2 Kota Pagar Alam menyambut baik terlaksananya pengabdian ini. 
Selain itu Kondisi geografis dan fasilitas teknologi informasi yang belum memadai di Pagar Alam berimbas pada tingkat pemahaman dan penalaran terhadap sesuatu hal baru agak terhambat, STT Pagar Alam sebagai Pionir dan dianggap lembaga yang kompeten terus mengikuti perkembangan teknologi informasi yang ada, dan kewajiban melakukan pengabdian seperti yang di amanatkan oleh jargon Tri dharma di atas, maka di adakanlah pengabdian yang kegiatannya pelatihan maintenance ini, sebenarnya upaya untuk berbagi dan saling memahamkan terhadap suatu ilmu yang di rasa oleh Para siswa dan Guru SMKN 2 Kota Pagar Alam kurang.

Dari pemaparan diatas dituntutagar para siswa SMKN 2 Kota Pagar Alam harus selalu meningkatkan kualitas pemahaman terhadap Teknologi informasi dengan menggunakan semua resource terkait, sehingga dipandang perlu untuk diadakan pelatihan Maintenance di lingkungan SMKN 2 Kota Pagar Alam ini.

\section{METODE.}

Pelaksanaan pengabdian ini dilakukan dosen STTP dilakukan secara mandiri, dan berbarengan dengan kuliah kerja nyata $(\mathrm{KKN})$ yang dilakukan mahasiswa sehingga dalam pelaksanaanya mahasiswa membantu dosen yang melaksanakan pengabdian. Metodologi yang digunakan pada pelaksanaan kegiatan Pengabdian kepada masyarakat (PkM) ini adalah menyimak (menonton) bersama, membaca bersama (modul pelatihan), memahami tools aplikasi (Software) dan berinteraksi secara langsung (Aplikatif) dengan software. Harapan dengan langkah ini peserta benar-benar bisa.

\subsection{Pengabdian Pada Masyarakat (PkM).}

Pengabdian masyarakat (PkM) adalah suatu kegiatan yang bertujuan membantu masyarakat tertentu dalam beberapa aktivitas tanpa mengharapkan imbalan dalam bentuk apapun. Secara umum program ini dirancang oleh berbagai universitas atau institut yang ada di Indonesia untuk memberikan kontribusi nyata bagi bangsa Indonesia, khususnya dalam mengembangkan kesejahteraan dan kemajuan bangsa Indonesia. Kegiatan Pengabdian Masyarakat merupakan salah satu bagian dari Tri Dharma Perguruan Tinggi (PT). Bentuk-bentuk kegiatan Pengabdian Masyarakat (PkM): Bakti Sosial dan Mengajar. Tujuan Pengabdian Masyarakat (PkM) di Perguruan Tinggi:

1. Menciptakan inovasi teknologi untuk mendorong pembangunan ekonomi Indonesia dengan melakukan komersialisasi hasil penelitian;

2. Memberikan solusi berdasarkan kajian akademik atas kebutuhan, tantangan, atau persoalan yang dihadapi masyarakat, baik secara langsung maupun tidak langsung;

3. Melakukan kegiatan yang mampu mengentaskan masyarakat tersisih (preferential option for the poor) pada semua strata, yaitu masyarakat yang tersisih secara ekonomi, politik, sosial, dan budaya;

4. Melakukan alih teknologi, ilmu, dan seni kepada masyarakat untuk pengembangan martabat manusia dan kelestarian sumber daya alam.

\subsection{Teknologi Informasi.}

Teknologi Informasi berasal dari kata Information Technology. Kata Technology berdasarkan Kamus Advanced Leaner's Dictionary of Current English (1974) adalah penerapan pengetahuan secara sistematis pada tugas-tugas praktis dalam suatu industri. Senada dengan definisi tsb, Sulistyo-Basuki (1992:81) menyatakan bahwa Teknologi dapat diartikan sebagai pelaksanaan ilmu, sinonim dengan ilmu terapan.

Kata Informasi dalam Oxford Advanced Learners's Dictionary of Current English (1980: 437), diartikan sebagai sesuatu yang diberitahukan, pengetahuan, dan berita. Sedang dalam Ilmu Informasi, kata-kata "Informasi", "pengetahuan", dan "berita" dibedakan. Menurut Teskey (dalam Pendit,1992) data adalah hasil observasi langsung terhadap suatu kejadian, yang merupakan perlambangan yang mewakili objek atau konsep dalam dunia nyata, yang dilengkapi dengan nilai tertentu; Informasi adalah kumpulan data yang terstruktur, yang disampaikan seseorang kepada orang lain. Sedangkan berita menurut Arifin (1997), adalah informasi yang menarik, penting, dan belum pernah didengar. Informasi merupakan sarana baku untuk menunjang dan meningkatkan kegiatan bidang Ilmu Pengetahuan, kebudayaan, dan teknologi. Pengetahuan, adalah sesuatu yang 
digunakan manusia untuk memahami dunia, yang dapat diubah-ubah berdasarkan informasi yang diterima. Dalam makalah ini informasi secara singkat diartikan sebagai segala data, fakta, dan pengetahuan yang disampaikan kepada orang lain melalui berbagai media, dalam bentuk tekstual, gambar, maupun suara.

Teknologi informasi merupakan sebuah istilah baru yang merupakan terjemahan dari Information Technology Bagi kebanyakan orang teknologi informasi merupakan sinonim dari "Teknologi Baru", karena karena kaitannya yang erat dengan mesin-mesin microprosesor., seperti mikro-komputer, alat-alat yang bekerja secara otomatis, seperti alat pengolah kata, dan lain sebagainya . Pengertian Teknologi Informasi berdasarkan British Advisory Council for Applied Research and Development (Dalam Zorkoczy, (1990: 12).adalah meliputi bidang-bidang ilmu pengetahuan, teknologi dan perekayasaan serta teknik-teknik pengelolaan yang digunakan dalam penanganan dan pengolahan informasi, penerapan bidang dan teknik tersebut, komputer dan interaksinya dengan manusia dan mesin, masalah sosial ekonomi serta budaya yang berkaitan. Memang banyak definisi-definisi tentang Teknologi Informasi, sehingga dalam "Macmillan Dictionary of Personal Computing and Communication" terdapat empat halaman yang menjelaskan tentang Teknologi Informasi.

\subsection{Maintenance.}

Maintenance merupakan kegiatan pemeliharaan dan perbaikan jika ada yang harus di perbaiki terhadap suatu perangkat atau sistem tertentu, dalam hal ini adalah sistem komputer, maintenance merupakan pemeliharaan atau perbaikan rutin, dengan adanya maintenance sistem komputer atau jaringan komputer dapat terhindar dari kerusakan yang sangat parah, karena sebelum terjadi kerusakan, hal-hal yang tidak diinginkan terjadi pada sistem komputer telah diantisipasi lebih dahulu.

\subsection{Pre \& Pos Tes.}

Pre Test yaitu suatu bentuk pertanyaan, yang dilontarkan guru kepada muridnya sebelum memulai suatu pelajaran. Pertanyaan yang ditanya adalah materi yang akan diajar pada hari itu (materi baru). Pertanyaan itu biasanya dilakukan guru di awal pembukaan pelajaran. Pre test diberikan dengan maksud untuk mengetahui apakah ada diantara murid yang sudah mengetahui mengenai materi yang akan diajarkan. Pre test juga bisa di artikan sebagai kegiatan menguji tingkatan pengetahuan siswa terhadap materi yang akan disampaikan, kegiatan pre test dilakukan sebelum kegiatan pengajaran diberikan. Adapun manfaat dari diadakannya pree test adalah untuk mengetahui kemampuan awal siswa mengenai pelajaran yang disampaikan. Dengan mengetahui kemampuan awal siswa ini, guru akan dapat menentukan cara penyampaian pelajaran yang akan di tempuhnya nanti.

Post test merupakan bentuk pertanyaan yang diberikan setelah pelajaran/materi telah disampaikan. Singkatnya, post test adalah evalausi akhir saat materi yang di ajarkan pada hari itu telah diberikan yang mana seorang guru memberikan post test dengan maksud apakah murid sudah mengerti dan memahami mengenai materi yang baru saja diberikan pada hari itu. Manfaat dari diadakannya post test ini adalah untuk memperoleh gambaran tentang kemampuan yang dicapai setelah berakhirnya penyampaian pelajaran. Hasil post test ini dibandingkan dengan hasil pree test yang telah dilakukan sehingga akan diketahui seberapa jauh efek atau pengaruh dari pengajaran yang telah dilakukan, disamping sekaligus dapat diketahui bagian bagian mana dari bahan pengajaran yang masih belum dipahami oleh sebagian besar siswa.

\subsection{Penyelesaian Masalah.}

Permasalahan yang dihadapi SMKN 2 Kota Pagar Alam adalah kurangnya efektifnya waktu belajar siswa sehingga tidak terlalu memahami maintenance komputer didalam kelas karena dikelas harus mempelajari banyak mata pelajaran, padahal bagi konsentrasi komputer, maintenance mata pelajaran yang harus benar-benar dikuasai, sehingga SMKN 2 Kota Pagar Alam bersama STTP mengadakan pelatihan maintenance bagi siswa untuk menambah softskills mendukung sistem belajar didalam kelas, PkM dilakukan diluar jam pelajaran oleh civitas STTP yang melakukan pengabdian, sehingga tidak mengganggu jam belajar siswa, tidak menambah beban kerja dari guru mata pelajaran. 


\section{PEMBAHASAN DAN HASIL.}

3.1. Realisasi \& Pemecahan Masalah.

Pengabdian (Pkm) dilaksanakan selama satu hari, melalui observasi dan pendekatan yang konprehensif terhadap sistem pembelajaran yang ada pada SMKN 2 Kota Pagar Alam, melalui observasi dan dialog dengan pimpinan SMKN 2 Kota Pagar Alam diperoleh satu kesimpulan bahwa pengabdian yang dilakukan Civitas STTP berdasarkan kebutuhan adalah pelatihan maintenance sistem komputer untuk menambah softskills siswa, sehingga sesuai estimasi waktu pengabdi dan SMKN 2, pelatihan dilaksanakan satu hari penuh dibantu oleh beberapa mahasiswa peserta KKN.

Pada pelaksanaannya pelatihan didahului dengan pre tes, tujuannya untuk mengetahui tingkat pemahaman para siswa peserta pelatihan terhadap maintenance komputer, peserta wajib mengikuti pre tes ini agar dalam pelaksanaannya materi yang disampaikan narasumber menjadi sesuai dengan kebutuhan dari peserta pelatihan sehingga waktu pelatihan menjadi efisien, berikutnya dikenalkan tools dan fitur komputer, fungsi serta cara kerjanya, dijelaskan juga apa bila terjadi permasalahan pada pada fitur (perangkat keras) komputer itu dan cara mengatasinya. Selanjutnya diperkenalkan tips dan trik maintenance, cara mereset terhadap beberapa perangkat keras dan perangkat lunak yang sederhana, bug, error dan sebagainya.

Berikutnya diperkenalkan juga tips dan trik untuk instalasi sistem operasi atau pun untuk software pendukung lainnya agar, aplikasi-aplikasi tidak menjadi crash, aplikasi-aplikasi tidak diperlukan tidak menjadi sampah-sampah dalam sistem komputer sehingga tidak membebani sistem memori komputer, terakhir dari pelatihan yang dilakukan ini adalah pos tes, post tes dilakukan untuk mengetahui seberapa efektif dan sejauh mana peserta pelatihan memahami materi pelatihan yang disampaikan oleh narasumber, tes ini pun diikuti oleh seluruh peserta pelatihan hasilnya menjadi bahan masukan bagi pengabdi, SMKN 2 dan tentunya LPPM STTP sebagai penanggung jawab kegiatan pengabdian secara Institusi. Yang mana susunan acara kegiatan PkM tersebut diuraikan tabel dibawah ini:

Tabel 1. Susunan Acara

\begin{tabular}{|c|l|c|}
\hline Waktu & \multicolumn{1}{|c|}{ Materi } & Penyaji \\
\hline $08.00-09.00$ & Pre Test & \\
$09.00-09.30$ & Persiapan dan pengenalan tools \& fitur komputer & \\
\cline { 1 - 2 } $09.30-12.00$ & $\begin{array}{l}\text { Mempelajari set up dan tips serta trik maintenance } \\
\text { Sederhana, reset bios, tips dan trik instalasi. }\end{array}$ & \\
$12.00-12.30$ & Oshoma & \\
$12.30-13.00$ & Post-test & \\
\hline
\end{tabular}

\subsection{Pembahasan \& Hasil.}

Berdasarkan urutan pelaksanaan pengabdian $(\mathrm{PkM})$ yang dilaksanakan diatas yang terdeskripsi didalam tabel 1, dalam poin 3.1 Maka berikut ini merupakan uraian keberhasilan yang didapatkan dari pelaksanaan pengabdian yang dilaksanakan pada SMKN 2 Kota Pagar Alam adalah sebagai berikut, yang mana pada pelaksanaannya peserta harus diberikan pemahaman bukan hanya aplikasi tetapi pemahaman dasar tentang maintenance dan permasalahan lain yang terkadang terjadi pada sistem komputer, pada tabel 2 .

Tabel 2. Keberhasilan Pelaksanaan Kegiatan

\begin{tabular}{|l|l|}
\hline \multicolumn{1}{|c|}{ Materi } & \multicolumn{1}{|c|}{ Hasil } \\
\hline Pendahuluan & $\begin{array}{l}\text { Peserta memahami dengan baik rencana dan tujuan } \\
\text { pelatihan sehingga menjadi fokus apa yang harus } \\
\text { dipelajarinya, pada tahap ini dilakukan pre tes. }\end{array}$ \\
\hline Pengenalah hardware \& software & $\begin{array}{l}\text { Seluruh peserta paham dengan baik seluruh perangkat keras } \\
\text { dan lunak komputer dan fungsinya sehingga tidak ada salah } \\
\text { paham tentang fungsi suatu alat yang ada didalam }\end{array}$ \\
\hline
\end{tabular}




\begin{tabular}{|l|l|}
\hline Tips dan trik maintenance & komputer. \\
\hline Tips, trik reset, instalasi software & $\begin{array}{l}\text { Peserta mengenali dan dapat memperkirakan permasalahan } \\
\text { sederhana yang ada pada komputer }\end{array}$ \\
\hline Penutup & $\begin{array}{l}\text { Peserta mampu melakukan intalasi dan meremov aplikasi } \\
\text { yang tidak diperlukan (Spam/sampah) }\end{array}$ \\
\hline $\begin{array}{l}\text { Pada bagian ini untuk mengetahui tingkat pemahaman } \\
\text { siswa terhadap materi. }\end{array}$ \\
\hline
\end{tabular}

Tabel 1, dan 2 menjelaskan pelaksanaan dan menjawab realisasi pengabdian dari permasalahan yang dihadapi oleh SMKN 2 Kota Pagar Alam, dari pelaksanaan pre tes diketahui secara toritis dan pemahaman awal siswa peserta pelatihan sudah paham dengan maintenance, tetapi pada saat praktek dengan komputer semua peserta masih bingung dan memerlukan pembelajaran tambahan sehingga pelatihan menjadi sangat diperlukan diadakan, berikutnya setelah tes para siswa kembali dikasih penjelasan tentang teknis dari perangkat keras dan lunak komputer lalu di perlihatkan komponen komputernya yang dibahas sehingga siswa benar-benar paham terhadap perangkat keras dan lunak yang ada, tip dan trik cara mengatasi permasalahan yang mungkin terjadi, tanda atau kode bunyi atau tanda lampu yang ada pada komputer diperkenalkan dengan baik, sehingga diakhir pelatihan dari hasil pos tes diketahui $100 \%$ peserta pelatihan memahami dengan baik materi yang disampaikan oleh narasumber, sehingga bisa diidentifikasi berikut merupakan hasil akhirnya, yaitu:

a. Para peserta siswa dan siswi SMKN 2 Kota Pagar Alam mempunyai pengetahuan dan pemahaman yang baik tentang Maintenance.

b. Seluruh siswa dan siswi SMKN 2 Kota Pagar Alam menjadi sangat paham terhadap teknologi informasi yang lebih aplikatif untuk mendukung kegiatannya.

c. Para guru SMKN 2 Kota Pagar Alam sudah terbantu dalam pemberian pemahaman terhadap teknologi informasi up to date yang aplikatif.

d. Para siswa dan siswi peserta pelatihan lebih memahami lagi tentang aplikasi pembelajaran TIK yang disampaikan oleh guru didalam kelas, jauh lebih memahami secara lebih aplikatif dalam Maintenance.

e. Para siswa siswi peserta menjadi lebih merasa percaya diri saat terjun pada dunia kerja dan lebih memiliki pemahaman pada siswa dan siswi yang melanjutkan studi keperguruan tinggi jelas pembelajaran ini menjadi pemahaman awal dalam bergaul pada perkuliahan di kampus.

\section{KESIMPULAN}

Pelaksanaan pengabdian masyarakat $(\mathrm{PkM})$ ini yang dilakukan di SMKN 2 Kota Pagar Alam dengan tujuan melatih siswa dan siswi dalam melakukan maintenance komputer didapatkan kesimpulan sebagai berikut:

a. Pembelajaran dengan cara belajar aplikasi secara langsung ternyata mampu meningkatkan semangat siswa belajar menjadi lebih baik (giat).

b. Menambah softskills siswa-siswi SMKN 2 Kota Pagar Alam dalam melakukan maintenance.

c. Meningkatkan perasaan percaya diri siswa karena kemampuannya ketika terjun di masyarakat.

d. Membantu guru pelajaran maintenance dalam hal memahamkan siswa terhadap suatu aplikasi tertentu.

\section{SARAN}

Berdasarkan pengalaman yang dilihat dan dirasakan penulis saat melakukan pengabdian ini maka, penulis dalam hal ini bisa memberikan saran:

a. Perlu waktu pengabdian dilakukan lebih lama sehingga materi benar-benar tersampaikan

b. Tempat pengabdian diperbanyak 


\section{UCAPAN TERIMA KASIH}

Penulis banyak mengucapkan terima kasih kepada Panitia KKN dan Pengabdian bagi Dosen, terima kasih kepada keluarga, kawan-kawan dosen, terima kasih kepada pihak SMKN 2 Kota Pagar Alam yang bersedia menjadi tempat pengabdian ( $\mathrm{PkM})$, terima kasih kepada keluarga penulis yang selalu mendukung.

\section{DAFTAR PUSTAKA}

[1] Hutchinson E. Sarah and Sawyer C. Stacey, 2000, Computers, Communications \& Information, McGraw Hill Companies Inc.

[2] Muslim, B. 2018. Pelatihan aplikasi editing video dengan filmora., Laporan Pengabdian Kepada Masyarakat, LPPM STT Pagaralam.

[3] Menristekdikti. 2016. Panduan Pelaksanaan Penelitian dan Pengabdian Masyarakat di Perguruan Tinggi Edisi X Tahun 2016. hlm. 4.

[4] Muslim, B. 2018. Pelatihan Pembuatan Blog Bagi Guru Ma Ponpes Darul Mutaqin Kota Pagaralam. NGABDIMAS. Vol 1. No.1. Bulan Juni, Hal. 6-11.

[5] B. Muslim, Pengantar teknologi informasi. Yogyakarta: Deepublish, 2017.

[6] Horsley, M., Knight, B., \& Huntly, H. 2010. The role of textbooks and other teaching and learning resources in higher education in Australia: Change and continuity in supporting learning. IARTEM 1-Journal. 3(2). 43-61.

[7] Sadiman, A.S., Rahardjo, R., Haryono, A., \& Rahardjito. 2006. Media pendidikan: Pengertian, pengembangan, dan pemanfaatan. Jakarta: Rajagrafindo Persada.

[8] Muslim, B. (2018). Analisis system informasi (SI) terintegrasi di Perguruan Tinggi (PT) (Studi Kasus: STT Pagaralam). Jurnal Teknologi Informasi MURA, Vol 10. Page 83-91.

[9] Muslim, B (2014). Analisis rencana aplikasi teknologi informasi pada STT Pagar Alam. Proseding semnastik dan Magma. Issue: Aplikasi Teknologi dan sistem Informasi. PPP UBD Pres. Pages 397-404.

[10] Indonesia Services Education HP Tim, 2001, Manajemen Sistem Belajar Di Dunia Maya, Majalah Info Komputer.

[11] M.H Jogiyanto, 1995, Pengenalan Komputer, Andi Offset Yogyakarta.

[12] Isro'Mukti, Y. (2017). Sistem Informasi Madrasah Aliyah Negeri Pagar Alam Berbasis Web. Indonesian Journal of Computer Science, 6(2), 192-205.

[13] Mukti, Y. (2017). Perencanaan Strategis Sistem Informasi Dan Teknologi Informasi Pada Sekolah Menengah Kejuruan Negeri 2 Pagar Alam. JURNAL ILMIAH BETRIK: Besemah Teknologi Informasi dan Komputer, 8(02), 83-92.

[14] Arif, A., \& Mukti, Y. (2017). Rancang Bangun Website Sekolah Menengah Pertama (SMP) Negeri 8 Kota Pagar Alam. JURNAL ILMIAH BETRIK: Besemah Teknologi Informasi dan Komputer, 8(03), 156-165.

[15] Isro'Mukti, Y. (2018, October). Sistem Informasi Manajemen Aset Sekolah Tinggi Teknologi Pagaralam Berbasis Web. In Seminar Nasional Teknologi Informasi dan Komunikasi (SEMNASTIK) (Vol. 1, No. 1, pp. 632-638).

[16] Mukti, Y. (2018). Rancang Bangun Website Sekolah Dengan Metode User Centered Design (UCD). JURNAL ILMIAH BETRIK: Besemah Teknologi Informasi dan Komputer, 9(02), 84-95.

[17] Mukti, Y. (2018). Pelatihan Maintance Komputer SMAN Pagar Gunung. NGABDIMAS, $1(1), 47-51$.

[18] Mukti, Y. I. (2019). Implementasi Jaringan Hotspot Kampus Menggunakan Router Mikrotik. Indonesian Journal of Computer Science, 8(2), 130-138.

[19] Mukti, Y. I., \& Puspita, D. (2019). Sistem Informasi Peringatan Dini Bencana Pada Kota 
Pagar Alam Berbasis Mobile. Jusikom: Jurnal Sistem Komputer Musirawas, 4(2), 65-74.

[20] Mukti, Y. I. (2019). SISTEM INFORMASI MONITORING KESEHATAN MASYARAKAT BERBASIS WEB MENGGUNAKAN METODE UNIFED MODELLING LANGUAGE. Jusikom: Jurnal Sistem Komputer Musirawas, 4(1), 1-8.

[21] Mukti, Y. I., \& Puspita, D. (2019, December). Web Based Disaster Early Warning System on Pagar Alam City. In Conference SENATIK STT Adisutjipto Yogyakarta (Vol. 5, pp. 309-316).

[22] Isro'Mukti, Y., \& Puspita, D. WEB BASED DISASTER EARLY WARNING SYSTEM ON PAGAR ALAM CITY.

[23] Puspita, D., \& Isro'Mukti, Y. (2019, December). Web-Based Culture Information System of Literature Besemah City of Pagar Alam. In Conference SENATIK STT Adisutjipto Yogyakarta (Vol. 5, pp. 303-308). 